\title{
Dr William Harvey (1578-1657): physician, obstetrician, and fetal physiologist
}

\author{
P M Dunn
}

William Harvey was born in Folkstone, Kent, in 1578 and educated first at the Grammar School in Canterbury and then at Caius College Cambridge (1593-7). In 1599, at the age of 21, he travelled to Padua where he studied for the next three years under such masters as Fabricius ab Aquapendente (Anatomy) and Galileo (Mathematics). After obtaining his doctor's degree with high distinction in 1602 he returned to England where he settled in London and married in 1604. The same year he became a member of the College of Physicians and in 1608 was appointed physician to St Bartholomew's Hospital. In 1615 he was made Lumleian lecturer to the College, a post he retained for life. The following year he gave his first dissertation on the circulation of blood, though his most famous work On the Motion of the Heart and Blood in Animals was not published until 1628. Meanwhile Harvey had been appointed physician to King James I (c 1618), and subsequently to Charles I. During the Civil War when the Court withdrew to Oxford, he was made Warden to Merton College (1642). In 1646 , when 66 years old, he resigned and withdrew from practice. His wife had died and as there had been no offspring, he went to live with one or other of his brothers. In 1651 the second of his great books, that $O n$ the Generation of Animals was published together with an essay On Parturition which was the first original English work on midwifery. In 1654 Harvey presented the College of Physicians with a new building. The same year he was elected President but gracefully declined the office because of his age and infirmities. He suffered badly from gout. So instead he was appointed Consiliari. He died three years later at the age of 79 and was buried in Hempstead, Essex.

So much for a bald outline of Harvey's life. For himself, he was a small person with dark eyes and an honest, cheerful countenance. A modest man, he lived in harmony and friendship with his colleagues. He was also a philosopher who liked nothing better than to withdraw to the attic or to a cavern in the garden in order to meditate. His contributions to medicine were immense. He introduced the experimental and observational approach to solving scientific problems and made tremendous contributions to comparitive anatomy and physiology, including embryology, as well as to

University of Bristol Southmead Hospital Correspondence to: Professor P M Dunn, Department of Child Health, Southmead Hospital Southmead Road, clinical medicine, surgery and obstetrics. Sadly most of his work was lost when a mob pillaged his home at the outbreak of the Civil War in

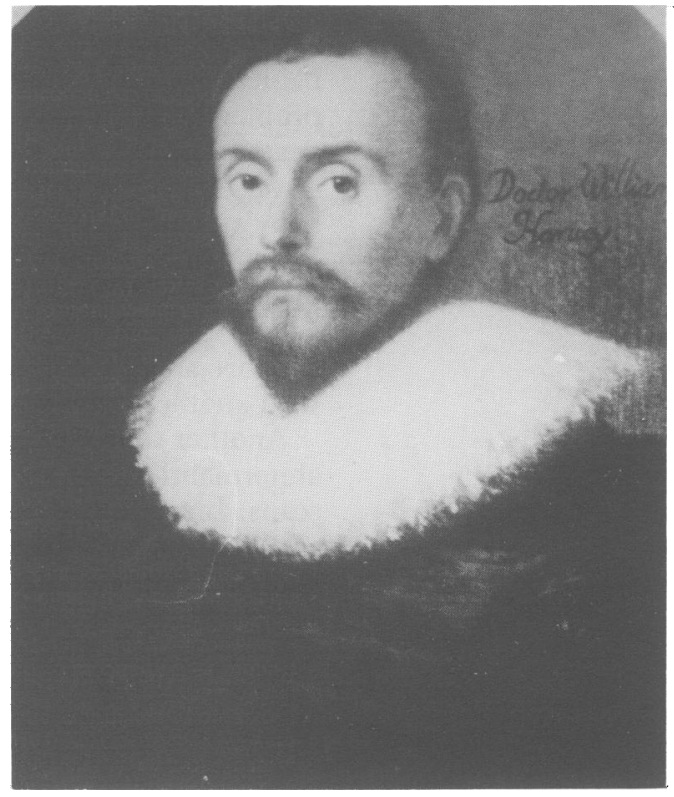

William Harvey in 1627.

1642 and much of the remainder was consumed when the College of Physicians was burnt in the Great Fire of London (1666). The extent of the loss may be gauged by anyone who takes the trouble to study his two remaining published works. They are truly remarkable when judged against the ignorance of the times and the prevalent reliance on ancient authority. Much space would be required to do justice to all his original observations and contributions. Of course, his dramatic exposition on the circulation, which for many years drew such scorn and abuse on his head, eventually achieved for him imperishable fame. Less well known but of similar importance were his observations on the nutrition of the fetus, on the significance of respiration, and on the perinatal circulation, as the following remarkable extracts reveal ${ }^{1}$ :

\section{On the placenta:}

'In my opinion, then, the placenta (has) an office analogous to that of the liver and mamma ... This adhesion, or growing together, first takes place, and the fleshy mass (constituting the bond of union between the "conception" and the uterus) is first produced, when the foetus becomes perfectly formed, and, through want either of different or more abundant nourishment, dispatches the extremities of the umbilical vessels to the uterus, that from 
hence, (as plants do from the earth by their radicles) it may absorb the nutrient juices . . . In truth, the "secundines" are part of the "conception", and depend upon it, borrowing thence their life and faculty of growth. For, just as in the mesentery, the blood is propelled to the intestines by the branches of the coeliac and mesenteric arteries, and returns thence by means of the veins to the liver and heart, together with the chyle, so in like manner do the umbilical arteries carry the blood to the secundines; which blood, together with the nutrient fluid, is brought back by the veins to the foetus . . . the orifices of the umbilical veins are in no way continuous with the uterine vessels ... the perfect coalition and union, described by Fabricius, never exist. Were it so, the veins and arteries ought to be continuous; for the vessels which bring the blood from the mother into the uterus and carunculae are arteries, whilst those which pass from the uterus to the foetus are veins, as is readily apparent; for they carry blood from the placenta into the vena cava'.

On the independent life of the fetus:

'In the Caesarean section, also, it is quite clear that the life of the embryo does not immediately depend upon the mother, and that the spirits do not proceed from her; for I have often seen the foetus extracted alive from the uterus when the mother has been dead some hours . . . Besides, in a tedious labour we learn whether the infant is alive or not by the pulsation of the umbilical arteries; and it is certain that these arteries receive their impulse from the heart of the foetus and not of the mother, for the rhythm of the two differs: this can be easily ascertained if one hand is applied to the wrist of the mother and the other to the umbilical cord. Nay, in the Caesarean section, when the embryo is still enveloped in the chorion, I have often found the umbilical arteries pulsating, and the foetus lively, even when the mother was dead and her limbs stiffened. It is not, therefore, true that the "spirits" pass from the mother to the foetus through the arteries; nor is it more so that the umbilical or foetal vessels anastomose with those of the uterus. The foetus has a proper life of its own, and possesses pulsating arteries filled with blood and "spirits", long before the "conception", in which it is formed and dwells, is attached to the uterus; just as it is with the chick in the egg'.

\section{On the fetal circulation:}

'In the embryo there is not such a difference between the two ventricles; but as in a double nut, they are nearly equal in all respects, the apex of the right reaching to the apex of the left, so that the heart presents itself as a sort of double-pointed cone. And this is so, because in the foetus, as already said, whilst the blood is not passing through the lungs from the right to the left cavities of the heart, but flowing by the foramen ovale and ductus arteriosus, directly from the vena cava into the aorta, when it is distributed to the whole body, both ventricles have in fact the same office to perform, whence their equality of constitution. It is only when the lungs come to be used and it is requisite that the passages indicated should be blocked up, that the difference in point of strength and other things between the two ventricles begin to be apparent: in the altered circumstances the right has only to throw the blood through the lungs, whilst the left has to impel it through the whole body.

Fabricius gives an elegant description, as well as most beautiful figures, of the umbilical vessles ... these penetrate the foetus at the umbilicus ... one vein of great size ... is inserted into the liver of the foetus, and has a communication both with the vena cava and vena portae. In like manner the arteries ... pass from the uterus towards the foetus, and, gradually uniting and increasing in size, terminate in two large trunks; these, after penetrating the umbilicus, separate from the veins, and attaching themselves to the lateral surface of the bladder by the intervention of a membrane, proceed downwards on either side and become continuous with the branches of the aorta descending to the thigh'.

\section{On fetal sucking:}

'The embryo, therefore seeks for and sucks in nourishment by the mouth; and you will readily believe that he does so if you rip him from his mother's womb and instantly put a finger in his mouth; which Hippocrates thinks he would not seize had he not previously sucked whilst in the womb. For we are accustomed to see young infants trying various motions, making experiments, as it were, approaching everything, moving their limbs, attempting to walk, and uttering sounds, acts all of which when taught by repeated experience, they afterwards come to execute with readiness and precision. But the foetus so soon as it is born, aye, before it is born, will suck; doubtless as it had done in the uterus long before. For I have found by experience that the child delayed in the birth, and before it has cried or breathed, will seize and suck a finger put into its mouth. A new-born infant, indeed, is more expert at sucking than an adult, or than he is himself if he have but lost the habit for a few days. For the infant does not suck by squeezing the nipple with his lips as we should, and by suction in the common acceptation; he rather seems as if he would swallow the nipple, drawing it wholly into his throat, and with the aid of his tongue and palate, and chewing, as it were, he milks his mother with more art and dexterity than an adult could practise. He therefore appears to have learned that by long custom, and before he saw the light, which we know full well he unlearns by a very brief discontinuance'.

\section{On the nature of respiration:}

'In the mean time I would propose this question to the learned-How does it happen that the foetus continues in its mother's womb after the seventh month? seeing that when expelled after this epoch, not only does it breathe, but without respiration cannot survive one little hour; whilst, as I before stated, if it remain in utero, it lives in health and vigour more than two months longer without the aid of respiration at all. To 
state my meaning more plainly-how is it that if the foetus is expelled with the membranes unbroken, it can survive some hours without risk of suffocation; whilst the same foetus, removed from its membranes, if air has once entered the lungs, cannot afterwards live a moment without it, but dies instantly? Surely this cannot be from want of "cooling", for in difficult labours it often happens that the foetus is retained in the passages many hours without the possibility of breathing, yet is found to be alive; when, however, it is once born and has breathed, if you deprive it of air it dies at once. In like manner children have been removed alive from the uterus by the Caesarean section many hours after the death of the mother; buried as they are within the membranes, they have no need of air; but as soon as they have once breathed, although they be returned immediately within the membranes, they perish if deprived of it. If any one will carefully attend to these circumstances, and consider a little more closely the nature of air, he will, I think, allow that air is given neither for the "cooling" nor the nutrition of animals; for it is an established fact, that if the foetus has once respired, it may be more quickly suffocated than if it had been entirely excluded from the air: it is as if heat were rather enkindled within the foetus than repressed by the influence of the air'.

1 Harvey W. The works of William Harvey. Translated from the Latin by $\mathbf{R}$ Willis. London: The Sydenham Society, 1847:1-624. 